\section{International Scientific Journal Theoretical \& Applied Science}

\author{
p-ISSN: 2308-4944 (print) e-ISSN: 2409-0085 (online) \\ Year: $2016 \quad$ Issue: 5 Volume: 37 \\ Published: $30.05 .2016 \quad$ http://T-Science.org
}

SECTION 23. Agriculture. Agronomy. The technique.
Svetlana Mikhailovna Dashkevich

$\mathrm{PhD}$ in Agriculture Science,

Head of Lab. of biochemistry and breeding for quality,

LLP "Scientific-Production Center of Grain Farming named after A.I. Barayev", Kazakhstan vetka-da@mail.ru

Irina Vladimirovna Chilimova Junior research assistant of Lab. of biochemistry and breeding for quality, LLP "Scientific-Production Center of Grain Farming named after A.I. Barayev", Kazakhstan, coronela@mail.ru

Nadezhda Ivanovna Filippova $\mathrm{PhD}$ in Agriculture Science, Head of Department of perennial grasses breeding, LLP "Scientific-Production Center of Grain Farming named after A.I. Barayev", Kazakhstan,

filippova-nady@mail.ru

Maral Uralovich Utebayev

Master of Natural Science,

Senior research assistant of Lab. of biochemistry and breeding for quality,

LLP "Scientific-Production Center of Grain Farming named after A.I. Barayev", Kazakhstan, phytochem@yandex.ru

\title{
STRUCTURAL CARBOHYDRATES CONTENT IN FEEDING MASS OF BREEDING SAMPLES OF PERENNIAL LEGUME GRASSES
}

Abstract: This paper presents the analysis of structural carbohydrates content in the feeding mass of breeding samples of three species of melilot and alfalfa, the best forms on detergent fiber content were selected, and they are the most valuable in breeding for quality.

Key words: melilot, alfalfa, sample, crude fiber, detergent fiber.

Language: Russian

Citation: Dashkevich SM, Chilimova IV, Filippova NI, Utebayev MU (2016) STRUCTURAL CARBOHYDRATES CONTENT IN FEEDING MASS OF BREEDING SAMPLES OF PERENNIAL LEGUME GRASSES. ISJ Theoretical \& Applied Science, 05 (37): 58-63.

Soi: http://s-o-i.org/1.1/TAS-05-37-12 Doi: crossef http://dx.doi.org/10.15863/TAS.2016.05.37.12

\section{СОДЕРЖАНИЕ СТРУКТУРНЫХ УГЛЕВОДОВ В КОРМОВОЙ МАССЕ СЕЛЕКЦИОННЫХ ОБРАЗЦОВ МНОГОЛЕТНИХ БОБОВЫХ ТРАВ}

Аннотация: В статье представлен анализ содержания структурных углеводов в кормовой массе селекционных образцов трех видов донника и лючерны, выделены лучшие по содержанию детергентной клетчатки формы, наиболее ценные для селекции на качество.

Ключевые слова: донник, лючерна, образеи, сырая клетчатка, детергентная клетчатка

\section{Введение}

Для жвачных животных основой рациона являются объемистые корма, в сухом веществе которых структурные углеводы занимают значительное место. Оценка кормовых культур, к которым относятся многолетние бобовые травы донник и люцерна, предусматривает определение содержания сырой клетчатки. Несмотря на то, что жвачные животные обладают сложной системой, приспособленной к перевариванию клетчатки, последняя далеко не полностью усваивается в пищеварительном тракте животных. Сырая клетчатка дает лишь приблизительное представление о различиях в степени переваримости кормов. Проблемой 
определения содержания сырой клетчатки является то, что в процессе химического анализа корма под действием кислот и щелочей часть гемицеллюлоз, целлюлозы и лигнина растворяется и фильтруется и при подсчете учитывается в БЭВ. Таким образом, истинная картина содержания углеводов искажается

В связи с разработкой метода фракционирования структурных углеводов Питером Ван Соестом появилась возможность более точно определять переваривание в желудочно-кишечном тракте животных каждой фракции углеводов.

Компоненты клеточных стенок сильно влияют на усвояемость кормов по мере взросления. Лигнин представляет собой барьер для пищеварения для жвачных животных и животных с однокамерным желудком [1,с. 175].

Поэтому необходимо проводить дифференцированные анализы, различающие компоненты клеточной оболочки, которые не растворяются в нейтральных детергентах (NeutralDetergentFibre $=\mathrm{NDF}$ ), и такие, как целлюлоза и лигнин, которые растворяются в кислых детергентах (AcidDetergentFibre=ADF). Для нормальной ферментации в рубце животных необходимо, чтобы в их рационах находился минимум этих структурных элементов [2, с. 56].

Нейтрально-детергентной клетчаткой (НДК) является сумма структурных углеводов клеточной стенки, состоящих из гемицеллюлоз, целлюлозы и лигнина. Кислотно-детергентная клетчатка (КДК)- целлюлоза + лигнин. НДК включает наибольшее число химических соединений по сравнению с сырой клетчаткой. В состав клеточной оболочки входит лигнин, который не является углеводом. Его доля растет с возрастом кормовых растений, чем снижается их кормовая ценность. Национальный исследовательский комитет США (NRC) рекомендует формировать рационы жвачных таким образом, чтобы в них на долю НДК объемистых кормов приходилось $75 \%$ от общего количества клетчатки.

Высокопродуктивным молочным коровам нужно сено, по крайней мере, $20 \%$ сырого протеина, менее $30 \%$ ADF, и менее чем на $40 \%$ NDF. Когда ADF составляет менее $25 \%$, и или NDF составляет менее 35\%, многие питательные вещества проходят через рубец без поглощения, по сути, впустую [1, с.175; 3, с. 686].

Определение волокон ткани, клеточных стенок с помощью кислотных детергентных средств и нейтральных детергентных средств является важным этапом в измерениях, используемых для определения качества корма, потребляемого животными. Фермеры используют эти расчеты, чтобы определить, сколько пищи требуется для животного и сколько энергии животное получит от потребляемой пищи [4 c. 809,5, c.1].

РН рубца и жевательная активность животных наиболее чувствительны к волокнам NDF[6, c. 652].

В процессе создания нового селекционного материала, сортов для оценки на качество следует использовать эти же, наиболее объективные характеристики.

\section{Материалы и методы исследования}

В качестве объекта исследований использована вегетативная масса сортов, коллекционных образцов, дикорастущих популяций донника и люцерны разных видов. В исследования привлекались 59 образцов донника волжского, желтого, белого и 66 образцов люцерны различного происхождения. Они характеризовались высоким качеством корма.

Определение содержания сырой клетчатки проводилось согласно ГОСТ 13496.2-91 Корма, комбикорма, комбикормовое сырье. Метод определения сырой клетчатки [7]. Сырая клетчатка представляет собой остатки от обработки растительных веществ слабыми кислотами и щелочами. Метод основан на окислении, разрушении и растворении различных химических соединений, входящих в состав растений, смесью концентрированных уксусной и азотной кислоты. При этом клетчатка практически не растворяется, отфильтровывается и взвешивается.

Для определения содержания нейтральнодетергентной клетчатки использовался ГОСТ ИСО 164-72 [8]. Сущность метода заключалась в растворении легкопереваримых белков, жиров, сахаров, крахмала, пектиновых веществ в кормах раствором нейтрального детергента и термостабильной альфа-амилазы, оставляя нерастворимый волокнистый осадок, представляющий собой компоненты клеточной стенки растительных материалов (целлюлоза, гемицеллюлоза, лигнин) и нерастворимое азотистое вещество в кормах животного происхождения.

Определение содержания кислотнодетергентной клетчатки проводилось в соответствии с СТ РК ИСО 13906-2011. Метод основан на удалении раствором кислотного детергента, неустойчивых к воздействию кислоты гидрокарбонатов, протеина, который не образует комплексов в виде продуктов реакции Майяра (поврежденных теплом), и жиров. Оставшийся волокнистый остаток представляет собой, главным образом, целлюлозу и лигнин.

Метод определения структурных углеводов основан на разделении корма на две фракции: растворимую в нейтральном детергенте и 
представляющую наиболее переваримую часть корма, состоящую из белков, жиров, углеводов, и нерастворимую в нейтральном детергенте, состоящую из гемицеллюлоз целлюлозы и лигнина, лигнифицированного азота и нерастворимой золы. Последующее воздействие на образец корма кислым детергентом позволяет добиться растворения гемицеллюлоз [9].

В задачу исследований входило определение содержания сырой, нейтрально и кислотно детергентной клетчатки и гемицеллюлозы в селекционных образцах донника для использования их в качестве родительских форм в селекции на качество.

\section{Результаты и их обсуждение}

Размах варьирования содержания сырой клетчатки по образцам донника был широким: от $13,18 \%$ в кормовой массе сорта Омский скороспелый до 23,94\% -сорта Еней (таблица 1).

Содержание структурных углеводов в кормовой массе образцов донника, урожай 2014 года

\begin{tabular}{|c|c|c|c|c|}
\hline \multirow[t]{2}{*}{ Сорт, номер } & \multicolumn{4}{|c|}{ Содержание, \% } \\
\hline & $\begin{array}{c}\text { сырой } \\
\text { клетчатки }\end{array}$ & $\begin{array}{l}\text { нейтрально- } \\
\text { детергентной } \\
\text { клетчатки }\end{array}$ & $\begin{array}{l}\text { кислотно- } \\
\text { детергентной } \\
\text { клетчатки }\end{array}$ & $\begin{array}{c}\text { гемицел- } \\
\text { люлозы }\end{array}$ \\
\hline Донник желтый ИК-2440 & 18,68 & 37,68 & 25,73 & 11,95 \\
\hline донник желтый Омский скороспелый (231) & 13,18 & 28,18 & 20,98 & 7,2 \\
\hline донник желтый КД-1699 & 15,52 & 25,56 & 19,67 & 5,89 \\
\hline Донник 14 желтый ИК-2745 & 18,30 & 22,40 & 18,09 & 4,31 \\
\hline донник желтый КД-1847 & 16,58 & 34,62 & 24,20 & 10,42 \\
\hline донник желтый КД-1596 & 18,50 & 31,84 & 22,81 & 9,03 \\
\hline донник желтый, КД-1819 & 18,66 & 30,06 & 21,92 & 8,14 \\
\hline донник желтый Омский скороспелый (213) & 16,46 & 26,36 & 20,07 & 6,29 \\
\hline донник желтый, КД-1841 & 16,94 & 29,28 & 21,53 & 7,75 \\
\hline донник желтый Омский скороспелый (261) & 18,22 & 27,24 & 20,51 & 6,73 \\
\hline донник желтый, КД-1369 & 19,38 & 32,16 & 22,97 & 9,19 \\
\hline донник желтый, ИК-2775 & 15,64 & 29,94 & 21,86 & 8,08 \\
\hline донник желтый, КД-1768 & 18,40 & 32,46 & 23,12 & 9,34 \\
\hline донник белый КД-1891 сорт Полещук & 21,74 & 29,56 & 21,67 & 7,89 \\
\hline донник белый КД-1892 сорт Еней & 23,94 & 30,66 & 22,22 & 8,44 \\
\hline донник белый КД-1891 сорт Полещук & 21,88 & 36,48 & 25,13 & 11,35 \\
\hline донник белый КД-1894 & 23,08 & 36,90 & 25,34 & 11,56 \\
\hline донник белый люцерновидный КД-1889 & 23,26 & 39,14 & 26,46 & 12,68 \\
\hline донник белый ИК-2793 & 20,58 & 39,56 & 26,67 & 12,89 \\
\hline донник белый ИК-2797 & 17,96 & 40,64 & 27,21 & 13,43 \\
\hline донник белый ИК-2851 & 23,34 & 44,00 & 28,89 & 15,11 \\
\hline донник белый ИК-2623 & 20,34 & 38,68 & 26,23 & 12,45 \\
\hline донник волжский, с. Акбас (242) & 20,52 & 34,60 & 24,19 & 10,41 \\
\hline донник волжский, КД-1687 & 19,62 & 36,24 & 25,01 & 11,23 \\
\hline донник волжский КД-1840 & 18,94 & 33,40 & 23,59 & 9,81 \\
\hline донник волжский КД-1690 & 17,50 & 28,02 & 20,90 & 7,12 \\
\hline донник волжский, с. Акбас (217) & 16,92 & 31,44 & 22,61 & 8,83 \\
\hline донник волжский КД-1793 & 18,20 & 36,04 & 24,91 & 11,13 \\
\hline донник волжский ИК-2603 & 18,50 & 35,24 & 24,51 & 10,73 \\
\hline донник волжский СП-08-09 дел 732 & 16,80 & 26,70 & 20,24 & 6,46 \\
\hline донник волжский, с. Барс & 19,00 & 30,38 & 22,08 & 8,3 \\
\hline донник волжский, КД-1807 & 19,38 & 30,70 & 22,24 & 8,46 \\
\hline донник волжский КД-1828 & 16,74 & 29,84 & 21,81 & 8,03 \\
\hline
\end{tabular}

В зависимости от вида донника количество структурных углеводов в изучаемых образцах изменялось в различных границах НДК - от 22,40 до $37,68 \%$, КДК - 18,09-24,2\%, гемицеллюлозы $4,31-10,42 \%$, у донника желтого соответственно $26,70-36,04 \%, \quad 20,24-24,91 \%, \quad 6,46-11,13 \% \quad y$

ISPC Science and mechanics, 


\begin{tabular}{l|lr|ll|ll} 
& ISRA (India) & $=\mathbf{1 . 3 4 4}$ & SIS (USA) & $=\mathbf{0 . 9 1 2}$ & ICV (Poland) & $\mathbf{= 6 . 6 3 0}$ \\
Impact Factor: & ISI (Dubai, UAE) $=\mathbf{0 . 8 2 9}$ & PUHL (Russia) $=\mathbf{0 . 2 3 4}$ & PIF (India) & $=\mathbf{1 . 9 4 0}$ \\
& GIF (Australia) & $=\mathbf{0 . 5 6 4}$ & ESJI (KZ) & $=\mathbf{1 . 0 4 2}$ & IBI (India) & $=\mathbf{4 . 2 6 0}$
\end{tabular}

донника волжского- 29,56-44,0\%, донника белого - 21,67-28,89\%, 7,89-15,11\% .

Более активное накопление структурных углеводов отмечено у донника белого, менее активное у донника волжского и желтого. Как наиболее высококачественные по детергентной клетчатке выделены образцы донника: желтого: ИК-2775 (29,94\%), КД-1819 (30,06\%), КД-1841 $(31,84 \%)$, волжского - д.217 с. Акбас $(31,44 \%)$, КД-1807 (30,70\%), белого - ИК-2623 (38,68\%), КД-1894 (36,90\%).

Чрезмерно высокое содержание в корме НДК снижает переваримость корма, а снижение

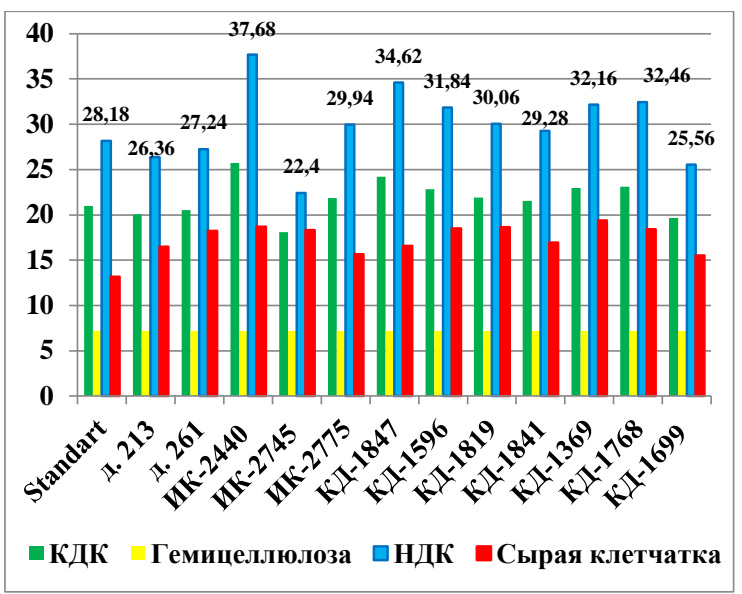

Донник желтый (a)
НДК в кормах до оптимального уровня обеспечивает соответственное повышение потребления сухого вещества рациона жвачными животными. Показателем качества НДК в корме является удельный вес в ней кислотнодетергентной клетчатки. Чем выше уровень КДК, тем ниже переваримость и в целом качество НДК и, как следствие, ниже потребление сухого вещества корма. На рис. 1 показана характеристика содержания фракций структурных углеводов и содержания сырой клетчатки в различных видах донника.

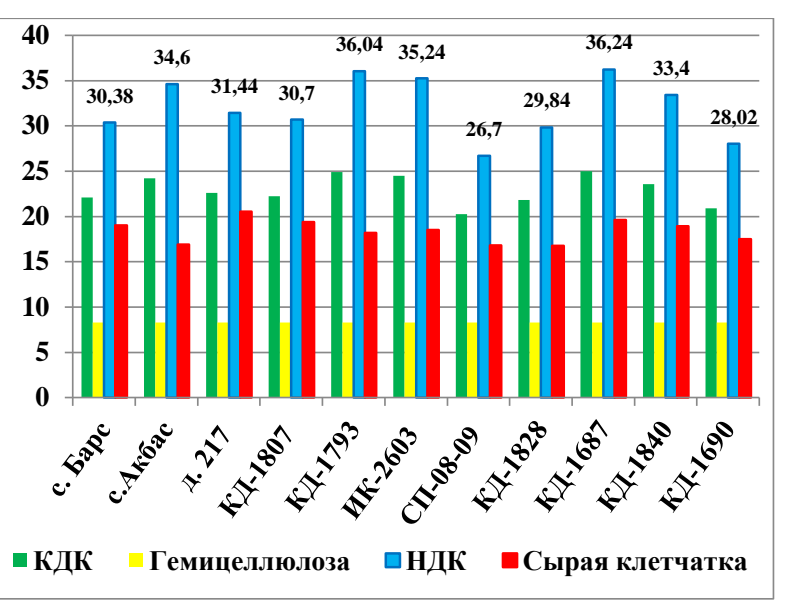

Донник волжский (b)

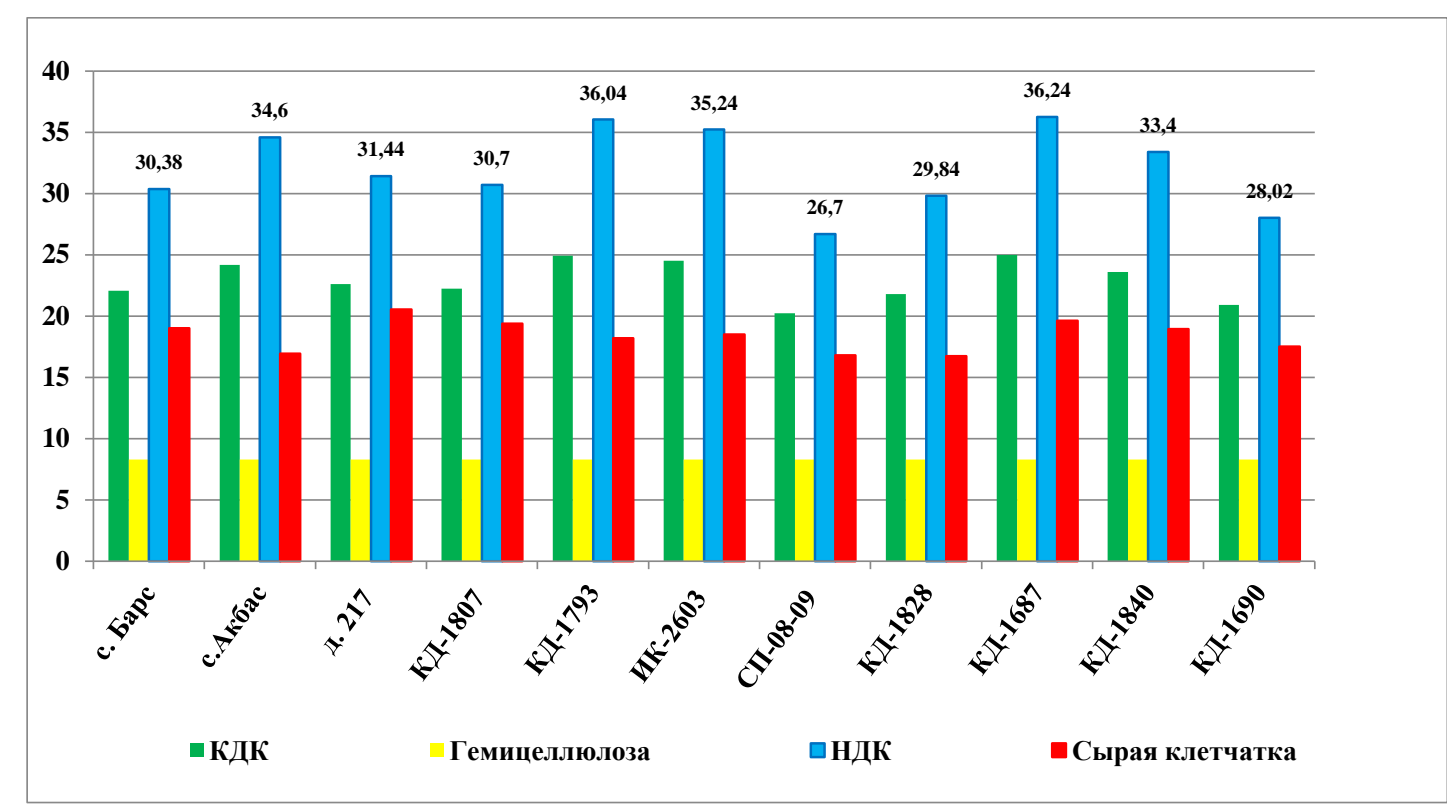

Донник белый (c)

Рисунок 1 - Содержание структурных углеводов в кормовой массе донника желтого (а), волжского (b), белого (c), урожай 2014 года.

Содержание сырой клетчатки в кормовой массе люцерны изменялось от $15,96 \%$ у СГП
1080 до 21,85\% у Л-1269, к -21770. В процессе исследований фракционного состава структурных

ISPC Science and mechanics, 
углеводов, установлено, что содержание НДК в изучаемых образцах люцерны колебалось от $19,62 \%$ до 43,88\%. Уровень КДК находился в пределах $16,7-28,83 \%$. Количество гемицеллюлозы варьировало от 2,92\% до 15,05\%. Содержание НДК у стандарта сорта Шортандинская 2 в среднем составило 39,12\%, КДК - 26,45\%, гемицеллюлозы - 12,67\%. Самый высокий уровень структурных углеводов отмечен у люцерны изменчивой К-21767 (43,88; 28,83; $15,05)$, низкий - К-1260 (19,62; 16,7; 2,92).

Наиболее высокие значения показателей НДК и КДК не соответствуют максимальному уровню содержания сырой клетчатки. Наиболее эффективным следует считать отбор для целей селекции по детергентной клетчатке.

В соответствии с рис. 2 показана характеристика содержания структурных углеводов в кормовой массе люцерны.

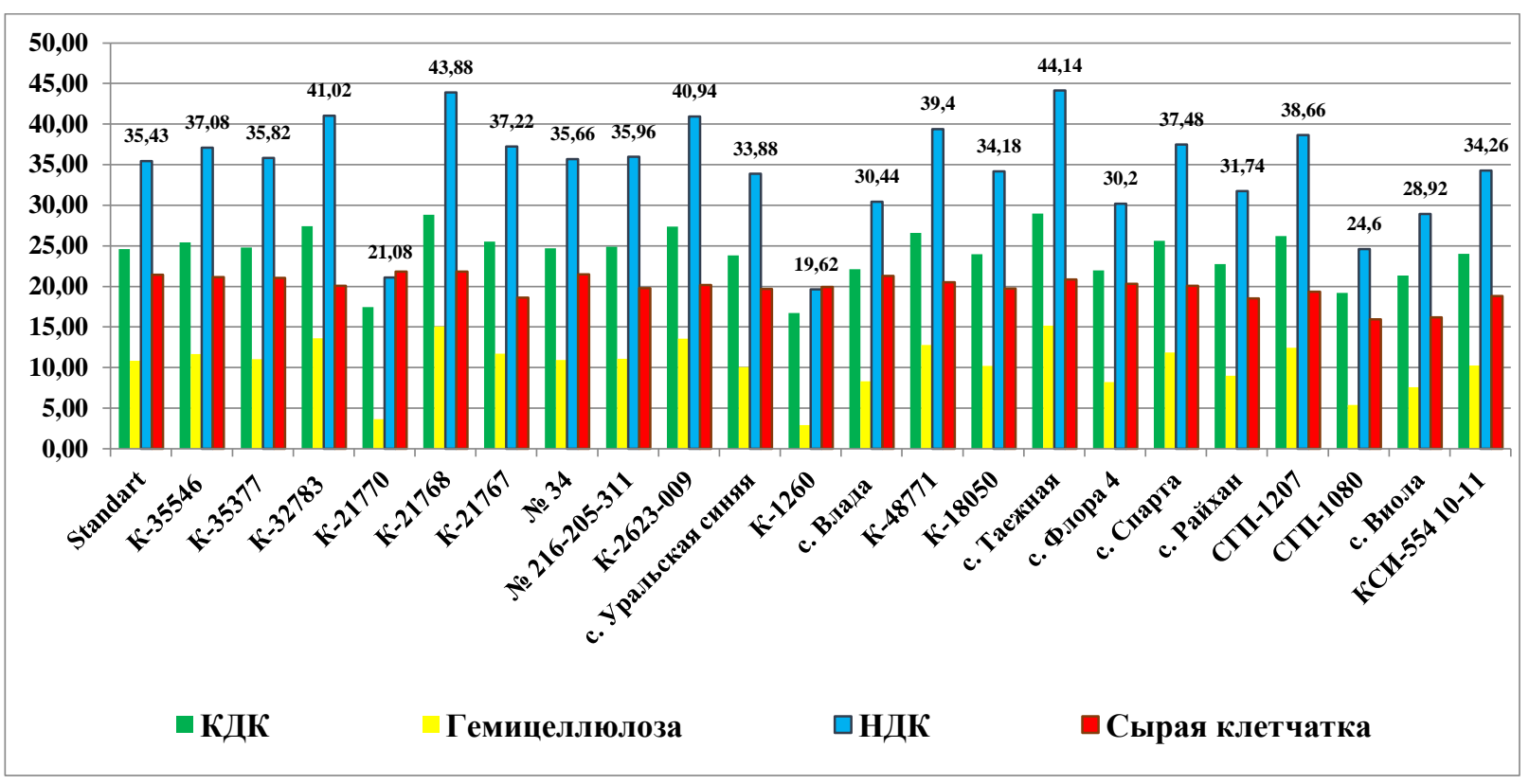

Рисунок 2 - Содержание структурных углеводов в кормовой массе люцерны, урожай 2014 года.

Согласно литературным данным чрезмерно высокое содержание в корме НДК выше 42\%, снижает переваримость корма, а снижение НДК в кормах до оптимального уровня обеспечивает соответственное повышение потребления сухого вещества рациона жвачными животными $[10$, с. 102]. В наших исследованиях $93 \%$ образцов люцерны выгодно отличились по содержанию структурных углеводов.

Таким образом, по содержанию детергентной клетчатки в кормовой массе донника выделены образцы, наиболее ценные для дальнейшей селекции на качество корма: донник: желтый: ИК-2775 (29,94\%), КД-1819 (30,06\%), КД-1841 (31,84\%), донник волжский - д.217 с. Акбас (31,44\%), КД-1807 (30,70\%), донник белый - ИК-2623 (38,68\%), КД-1894 (36,90\%). При аналогичной оценке кормовой массы люцерны установлен высокий уровень структурных углеводов люцерны изменчивой К-21767 (НДК43,88;КДК 28,83; гемицеллюлоза -15,05).

\section{References:}

1. Baurhoo B, Ruiz-Feria CA, Zhaoa X (2008) Purified lignin: Nutritional and health impacts on farm animals-A review.- Animal Feed Science and Technology 144 (2008) 175-184. 


\begin{tabular}{|c|c|c|c|c|c|c|}
\hline Impact Factor: & $\begin{array}{l}\text { ISRA (India) } \\
\text { ISI (Dubai, UAE } \\
\text { GIF (Australia) } \\
\text { JIF }\end{array}$ & $\begin{array}{l}=1.344 \\
=0.829 \\
=0.564 \\
=1.500\end{array}$ & $\begin{array}{l}\text { SIS (USA) } \\
\text { PИНЦ (Russia) } \\
\text { ESJI (KZ) } \\
\text { SJIF (Morocco) }\end{array}$ & $\begin{array}{l}=0.912 \\
=0.234 \\
=1.042 \\
=\mathbf{2 . 0 3 1}\end{array}$ & $\begin{array}{l}\text { ICV (Poland) } \\
\text { PIF (India) } \\
\text { IBI (India) }\end{array}$ & $\begin{array}{l}=6.630 \\
=1.940 \\
=4.260\end{array}$ \\
\hline
\end{tabular}

2. Diter Shpaar (2009) Fodder crops. DLV Agrodelo, Russia. 464 pp.

3. Krieg R, Martienssen M, Zentek J (2012) Effect of the ratio lignin to cellulose (Adf - Adl) on caecal fermentation gut morphology and performance of rabbits around World Rabbit Science Association Proceedings 10 th World Rabbit Congress - September 3 - 6, 2012Sharm El- Sheikh -Egypt, 685 - 689.

4. Bidlack JE, Buxton DR (1992) Content and deposition rates of cellulose, hemicellulose, and lignin during regrowth of forage grasses and legumes.- Canadian Journal of Plant Science, 1992, 72(3): 809-818 (1).

5. (2016) Differences Between an Acid Detergent Fiber \& a Neutral Detergent Fiber eHow_com.mht

6. Zebeli Q, Tafaj M, Steingass H, Metzler B, Drochner W (2006) Effects of physically effective fiber on digestive processes and milk fat content in early lactating dairy cows fed total mixed rations. $2006 \mathrm{Feb} ; 89(2): 651-68$.

7. (1992) State Standard 13496.2-91. Feed, Compound Feeds, Mixed Feed Raw Products.
Crude Fiber Method. - Instead Of State Standard 13496.2-84; put in 07/01/1992. Minsk. Interstate Council For Standardization, Metrology and Certification; Moscow: Publishing House of Standards, 3.

8. (2013) ISO Standard 16472. Animal Feed. Determination of Neutral Detergent Fiber Content (aNDF) with Amylase Using. - Minsk: Eurasian Council For Standardization, Metrology and Certification; Minsk: 2013

9. (2012) The Republic of Kazakhstan ISO Standard 13906-2011. Animal Feed. Determination of Fiber and Lignin with an Acidic Detergent. - put in 2012-07-01. Astana: The Committee of Technical Regulation and Metrology; Astana: State Standard, 24.

10. Kurepin AA (2012) Influence of Fractional Composition of Fiber on Digestibility and Nutrients Utilization by Cows / A.A Kurepin, A.I. Sahanchuk // Newsletter of Agrarian Science in Black Sea region. Iss. 4 (70), vol. 2, Part 2: 101-105. 